\title{
Stress-state dependence of dynamic strain aging: Thermal hardening and blue brittleness
}

\author{
Wen-qi Liu ${ }^{1)}$ and Jun-he Lian ${ }^{1,2)}$ \\ 1) Advanced Manufacturing and Materials, Department of Mechanical Engineering, Aalto University, Puumiehenkuja 3, 02150 Espoo, Finland \\ 2) Impact and Crashworthiness Lab, Department of Mechanical Engineering, Massachusetts Institute of Technology, 77 Massachusetts Avenue, Cambridge, MA \\ 02139-4307, USA \\ (Received: 14 October 2020; revised: 31 December 2020; accepted: 11 January 2021)
}

\begin{abstract}
This study aims to discover the stress-state dependence of the dynamic strain aging (DSA) effect on the deformation and fracture behavior of high-strength dual-phase (DP) steel at different deformation temperatures $\left(25-400^{\circ} \mathrm{C}\right)$ and reveal the damage mechanisms under these various configurations. To achieve different stress states, predesigned specimens with different geometric features were used. Scanning electron microscopy was applied to analyze the fracture modes (e.g., dimple or shear mode) and underlying damage mechanism of the investigated material. DSA is present in this DP steel, showing the Portevin-Le Chatelier (PLC) effect with serrated flow behavior, thermal hardening, and blue brittleness phenomena. Results show that the stress state contributes distinctly to the DSA effect in terms of the magnitude of thermal hardening and the pattern of blue brittleness. Either low stress triaxiality or Lode angle parameter promotes DSA-induced blue brittleness. Accordingly, the damage mechanisms also show dependence on the stress states in conjunction with the DSA effect.
\end{abstract}

Keywords: dynamic strain aging effect; Portevin-Le Chatelier effect; damage mechanism; dimple fracture; shear fracture; dual-phase steel

\section{Introduction}

The dynamic strain aging (DSA) effect has been widely investigated since the middle of the 20th century because it strongly affects mechanical properties, including the strength and ductility of metals [1-5]. Early-stage investigations mainly focused on mild steel and iron under tension loading. The four basic characteristics of the DSA effect are as follows: (1) serrated flow behavior, (2) enhanced strength with temperature increase, (3) anomalous strain rate dependence, and (4) blue brittleness phenomenon [6]. The conventional understanding of the DSA effect is based on Cottrell atmosphere theory [7-8]. At a specific temperature and strain rate range, the solute atoms could diffuse and segregate to the dislocation core, which forms the Cottrell atmosphere and pins the dislocation movement. For dislocations to break away from the solute cloud, external stress is required to reactivate the dislocation movement. The repeated interaction between dislocations and solute atoms results in the serrated plastic flow and strain localization bands on the material surface; this phenomenon is known as the Portevin-Le Chatelier (PLC) effect [9]. The induced extra resistance to dislocation mobility also results in enhanced strength with temperature increase (referred to as thermal hardening in the present study) and negative strain rate sensitivity within a specific temperature and strain rate range. The consequent blue brittleness is also related to the dislocation-solute atom interaction. However, a clear explanation has been lacking in the literature. The blue brittleness behavior of mild steel under torsion loading is related to the diffusion rate and concentration of the carbon or nitrogen atoms [10]. In addition, different blue brittleness behavior under static and dynamic loading is observed, whereas a considerably high dislocation density under dynamic loading is expected [11].

With the development of modern steel with additional alloying concepts and microstructure features and experimental techniques, investigations on DSA have been enhanced in recent decades. The understanding of the DSA mechanism becomes increasingly important as DSA-related phenomena occur in many commercial-grade steels and various applications, which mostly bring detrimental performance during service (e.g., increased surface localization and defects [12-13], reduction of ductility [14-15], fatigue life [16-17], and fracture resistance [18-19]). Previous studies have illus-

Corresponding author: Junhe Lian E-mail: junhe.lian@aalto.fi, lianjh@mit.edu (C) The Author(s) 2021 
trated that the DSA effect occurs not only in low-carbon steel (e.g., ferritic [20], martensitic [21], bainitic [19], and austenitic [22] steel) but also in high-carbon ones (e.g., pearlitic steel [23-24]). Furthermore, cementite decomposition could be related to the DSA effect in pearlite steel [23-24]. To obtain an improved understanding of DSA, scanning and/or transmission electron microscopy (SEM/TEM) techniques are normally used to assist investigations. An investigation on pure iron with in situ TEM indicated that pure screw dislocation locking could contribute to the DSA effect, and a new Peierls mechanism could be active at high temperatures [25]. A study on ferritic steel also identified the effect of screw dislocations in DSA [26]. The jerky flow behavior at low temperatures is caused by the conventional Cottrell dislocation-carbon atom interaction, whereas serrated flow curves at high temperatures are due to the strong screw dislocation-carbon interaction, which could result in straight screw dislocation lines. At DSA temperatures, distinctly high dislocation density, clear straight dislocation lines, less cellular structure but dense dislocation walls/tangles can be observed; these characteristics could be correlated to the restricted dislocation substructure rearrangement and enhanced dislocation multiplication caused by DSA [27]. In conclusion, the interaction between dislocation and solute atoms could lead to dislocation multiplication, increased dislocation density, and dense dislocation walls/cells, and the restricted dislocation cross-slip contributes to the planarity of dislocation glide.

For DSA behavior during the plastic deformation stage, the microscopic dislocation mechanisms have been well characterized. As previously reported, dislocation mechanisms considerably affect plastic deformation and the fracture behavior of steels; such influence could be observed via postmortem fractography of SEM. For example, dimple refinement was observed on most dimple dominated ductile fracture surface of steels [20-21] that failed at the DSA regime. The reasons could be related to the increased dislocation substructure density, which brings additional void nucleation sites [27]. Furthermore, the occurrence of shallow dimples is another common feature of the fractography at the DSA regime [20-21]. This occurrence is generally explained by a lack of void growth process and reduced crack growth resistance [27]. Except for dimples, ductile-tearing and brittle-like fractures were also observed in a high-martensite dual-phase (HMDP) steel within the DSA range [28]. In addition, the dislocation-carbon interaction could induce intergranular cracking and reduce the ductility in high-Mn steel [29]. The mixed transgranular and intergranular fracture modes were also observed in a 316L stainless steel under cyclic loading at the DSA regime [17]. As a result, the increased inhomogeneity, additional damage initiation, accelerated damage/crack propagation, featureless flat fracture surface, and premature fracture were enhanced by DSA.
Furthermore, from the perspective of mechanics, the understanding of DSA-related embrittlement was also developed. A common feature for DSA-related embrittlement is the fast crack propagation rate. Hong and Lee [16] concluded that the fast crack propagation rate could be related to the enhanced work hardening rate, which is often a result of the DSA. Another feature revealed by crack growth tests is periodic crack jumps [18] or the alternate tension-tear process [19] at the crack tip zone, indicating a repeated crack tip blunting and tearing. This feature could be attributed to the release of PLC bands during DSA, which may affect the extent of plastification at the crack tip. A lack of crack tip plastification would affect the relaxation of the crack tip stresses and lead to crack jump or tearing fracture [18]. An interesting feature of DSA-related embrittlement is that DSA manifestations are not always detrimental as opposed to the common blue brittleness behavior. Furthermore, fracture toughness is enhanced in the DSA regime for Armco iron [30]. Alomari et al. [31] also found increased ductility within the DSA range for austenitic steel.

Although substantial literature on DSA exists, DSA remains to be a constantly updated issue worthy of attention. For instance, for advanced high-strength steel, complex microstructures and service environments would bring new questions on DSA manifestation. A study on high-Mn twinning-induced plasticity steel suggested that DSA could be suppressed by increased stacking fault energy [32]. Moreover, DSA mechanisms in medium-Mn transformationinduced plasticity (TRIP) steel may have three kinds, including $\mathrm{Mn}$ ordering in the $\varepsilon$-martensite and austenite interface stacking faults, carbon diffusion and dislocation-Mn-C pair formation in $\gamma$-austenite, and dislocation interaction with nitrogen in $\alpha$-ferrite [33]. In terms of ferritic-martensitic dualphase (DP) steel, the DSA effect is mainly attributed to ferrite, whereas martensite or carbides do not affect the DSA behavior [34]. Several studies have also focused on the synergetic effect of DSA and hydrogen [35-38]. However, microstructure-level investigation on the DSA-related damage mechanism remains lacking, especially for DP steels. Moreover, stress state has a considerable influence on the ductile fracture for metallic materials, as revealed by microstructure-level damage mechanisms [39-41] and the observed mechanical tests [42-44]; however, the focused stress state for DSA-related case is typically uniaxial tensile or compression tests under either monotonic or cyclic loading. DSA investigation still needs to explore a wide range of stress states other than uniaxial tension or compression.

Therefore, this study aims to discover the stress-state dependence of the DSA effect in a DP steel at different deformation temperatures and reveal the damage mechanisms under these various stress states in conjunction with the DSA effect. The investigation covers a testing temperature range from room temperature (RT) up to $400^{\circ} \mathrm{C}$, keeping loading under 
quasistatic conditions. The two major characteristics of the DSA behavior explored in the current study are thermal hardening and blue brittleness. The various stress states include the typical uniaxial tension, as well as simple shear and plane-strain (PS) tension, and the ones in-between, which could be often met during material forming applications or in-service loading. Tests with specific featured stress states vary from simple shear to plane-strain tension. The DSA behavior is first characterized under the uniaxial tension condition by tensile tests, where yield strength (YS), ultimate tensile strength (UTS), uniform elongation (UE), and fracture elongation (FE) are the main measures. For other tests with extended stress states from uniaxial tension, a specific experimental program with featured sample geometries is designed and implemented via creating notches and cuts on typical dog-bone tensile samples. Peak force, peak-force displacement, and fracture displacement are considered to characterize the DSA effect. After mechanical testing, the ductile damage mechanisms in conjunction with the DSA effect under varying loading conditions are analyzed by postmortem SEM fractography, as well as metallography on the lateralcut specimen planes right beneath the fracture surfaces. The results could provide information on microstructure features at damage initiation.

\section{Experimental}

An advanced high-strength automotive DP steel (DP1000) sheet with a thickness of $1.5 \mathrm{~mm}$ was selected as the investigated material in this study. It consists of 55\% ferrite and $45 \%$ martensite. Detailed microstructural information was given in a previous study by Liu et al. [45].

\subsection{Experimental program}

The experimental program consisted of two groups of mechanical tests: uniaxial tensile tests with smooth dog-bone (SDB) specimens and tensile tests with featured specimens. For the first group test with SDB specimens, five temperatures $\left(25,100,200,300\right.$, and $\left.400^{\circ} \mathrm{C}\right)$ were chosen under a strain rate of $10^{-4} \mathrm{~s}^{-1}$.

For the second group of tests, six featured dog-bone specimens with different notches and cuts were used, as shown in Fig. 1. The specific geometric features were created to trigger a specific stress state at the crack initiation point to investigate the stress-state dependency of fracture. For the characterization of stress states, two dimensionless variables, namely, stress triaxiality and Lode angle parameter, were used; the detailed definition and interpretation of these variables could be found in several studies [46-47]. Under monotonic loading, the crack initiation point usually coincides with the material point that undergoes the most plastic deformation and is often referred to as the critical point of the specimen because it also suffers from the most damage. To identify the position of the critical point and ensure that the stress state of this point is as desired and constant during deformation, numerical modeling is used for the design process. The detailed procedure and sample geometries for these designated stress states could be referred to in a previous study [48]. For the completeness of the current work, a summary is also provided. The six types of specimens can be further classified into four subgroups:

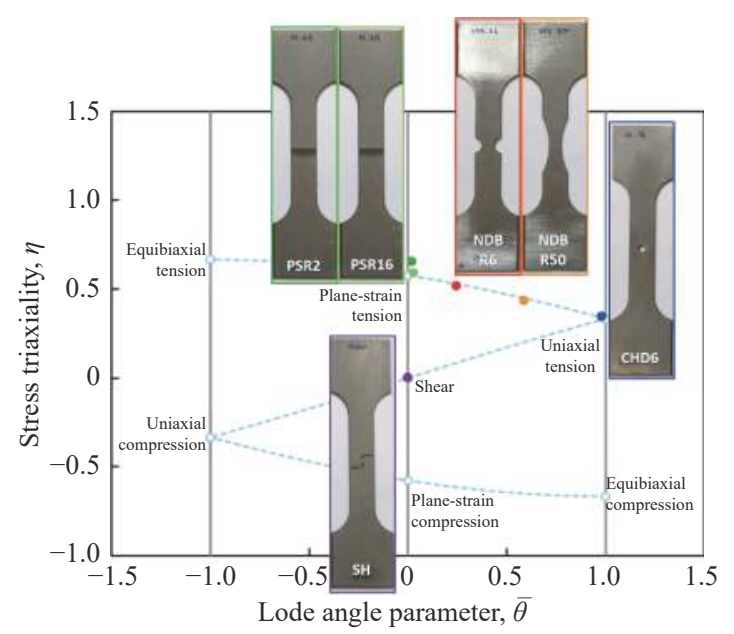

Fig. 1. Experimental testing plan for the investigation of the fracture behavior of DP1000 steel with all sample geometries and their corresponding stress states at the fracture.

(1) The central-hole $(\mathrm{CH})$ specimen with a hole diameter of $6 \mathrm{~mm}$ (CHD6) provides a constant uniaxial tension stress state at the critical point, which is located at the intersection point of the circular hole edge with the two symmetry planes in the thickness and length directions.

(2) The notched dog-bone (NDB) specimens correspond to the transition stress sates from uniaxial tension to planestrain tension at the critical point. The specimen with a large notch radius (NDBR50) tends more toward the uniaxial tension, whereas the one with a smaller notch radius (NDBR6) is closer to the plane-strain tension. The critical point for these specimens is at the center of the specimen.

(3) The plane-strain specimens provide a generalized plane-strain tension stress state at the critical point, which is also the central location of the specimen. The geometry with a larger out-of-plane notch radius (PSR16) has a rather lower stress triaxiality than the one with a smaller radius (PSR2).

(4) The shear (SH) specimen provides a simple shear stress state at the critical spot, which corresponds to an area at the center of the specimen in the mid-thickness plane.

These desired stress states are closely related to the critical point, implying that the entire deformation volume of the specimens is likely not subjected to the same stress state. A gradient of the stress state of the plastic deformation region is expected to exist in the featured specimens, whereas the critical point features a stable and constant stress state, with the 
only exception of NDB samples, where a certain evolution of the stress state could be found [48]. For the second group of tests, the chosen loading velocity was $0.2 \mathrm{~mm} / \mathrm{min}$ to ensure that a quasistatic condition was fulfilled at critical points. Four temperatures $\left(25,100,200\right.$, and $\left.300^{\circ} \mathrm{C}\right)$ were considered for all the six geometries, i.e., 24 groups of fracture tensile tests with featured stress states in total.

\subsection{Experimental procedures}

The tests were executed on a multifunctional testing machine installed with a temperature chamber manufactured by Zwick/Roell. All the specimens were loaded along the rolling direction (RD) according to EN ISO 6892-1:2016 [49]. The force was measured by the load cell, whereas the displacement was measured by one extensometer in conjunction with an optimal camera. An initially given distance between the extensometer was set along the RD. At least three parallel tests were conducted for each tensile test condition to ensure reliable measurement of the tests. For testing above RT, a temperature chamber where the temperature could reach up to $500^{\circ} \mathrm{C}$ via induction heating was used. During the test, real-time temperature was measured by two thermocouples located at the top and bottom parts of the specimen, directly on the specimen surface. These measurements were used to adjust the controlling system of the thermal chamber to ensure that the sample temperature was as desired and stayed stable during the test.

\subsection{Microstructure characterization}

SEM investigation was conducted on the featured-stressstate specimens after fracture to study the damage mechanisms of DP1000 under different loading conditions. Observations, including the fractographs on the fracture surfaces and the micrographs on the cross-section planes right beneath the fracture surface, were performed. In consideration of the effort for sample preparations and SEM measurements, only one sample for each stress state and loading condition was chosen in this study. The investigated specimens were CHD6, NDBR6, PSR16, and SH.

After the tests, the fracture surfaces of the two broken parts of specimens were covered by atomizing the anticorrosion coating. A small piece of the sample with a height of approximately $10 \mathrm{~mm}$ starting from the fracture surface was then cut by a disk saw for both broken parts. As a result, two pieces with the fracture surface for each fractured specimen were obtained. The first one was cleaned in an ultrasonic cleaner with alcohol and then placed in the SEM chamber for fractographic observation.

The second piece was used for the SEM micrographs taken beneath the fracture surface to investigate the microstructure-sensitive damage mechanism of DP1000. The observation positions were the critical damage initiation points of each geometry as described in Section 2.1. Therefore, the investigation of $\mathrm{CH}, \mathrm{NDB}$, and PS specimens focused on the through-thickness cross-section, i.e., RD-ND (normal direction) plane, whereas the RD-TD (transverse direction) plane was chosen for the SH specimen. For sample preparation, an additional cutting by electrical discharge machining for $\mathrm{CH}$, NDB, and PS was necessary. The cut was performed along the loading direction throughout the thickness at a position approximately $2 \mathrm{~mm}$ away from the focused points. For $\mathrm{SH}$, the specimen thickness was only $1.5 \mathrm{~mm}$, and the middle RD-TD plane was the observation position; thus, mechanical grinding was directly used for reduction to half-thickness. All SEM samples were carefully ground to the critical damage initiation planes. Then, mechanical polishing until $3 \mu \mathrm{m}$ and chemical etching with a $3 \%$ Nital solution were used to prepare the final observation surface. After etching, the ferrite and martensite phases can be distinguished on the SEM micrographs. The SEM observation was conducted on a Carl Zeiss GeminiSEM field emission gun scanning electron microscope.

\section{Results and discussion}

\subsection{DSA behavior of DP1000 steel under uniaxial tension}

Figs. 2(a)-2(b) show the engineering stress-strain curves for testing under quasistatic loading (strain rate of $10^{-4} \mathrm{~s}^{-1}$ ) at all five different temperatures. The yielding and flow stress slightly decrease from 25 to $100^{\circ} \mathrm{C}$ due to the normal thermal softening effect, and then an abnormal stress increase, referred to as thermal hardening, with a further temperature increase to 200 and $300^{\circ} \mathrm{C}$ is observed (Fig. 2(a)). Simultaneously, the serrated flow curves are also observed at $200-400^{\circ} \mathrm{C}$ (Figs. 2(a)-2(b)); this phenomenon is referred to as the PLC effect. In addition, blue brittleness (shortened ductility) appears at a temperature range of $100-200^{\circ} \mathrm{C}$, which are defined as blue temperatures. Figs. 2(c)-2(d) show the combination of flow curves (in solid lines) and strain hardening rate curves (in dot lines) until the UE points, from which the enhanced strain hardening rate at $300^{\circ} \mathrm{C}$ can be clearly observed. With strain evolution, the strain hardening rates of 100 and $200^{\circ} \mathrm{C}$ are larger than that of RT; even for $400^{\circ} \mathrm{C}$, when the plastic strain is larger than 0.04 , its hardening rate is higher than that of RT. Furthermore, the engineering and true stresses of $300^{\circ} \mathrm{C}$ are not always higher than $200^{\circ} \mathrm{C}$ (Figs. 2(b) and 2(d)), indicating the evolution of thermal hardening with plastic strain. All these phenomena indicate that DSA occurs in this DP steel at a specific temperature and plastic strain range. When temperature increases to $400^{\circ} \mathrm{C}$, the flow stress-temperature behavior returns to the normal correlation, under which the thermal softening behavior becomes dominant again.

Detailed analyses on the characteristic features of tensile properties, including YS, UTS, UE, and FE, are summarized in Figs. 2(e)-2(f). Data are plotted as the average values with 

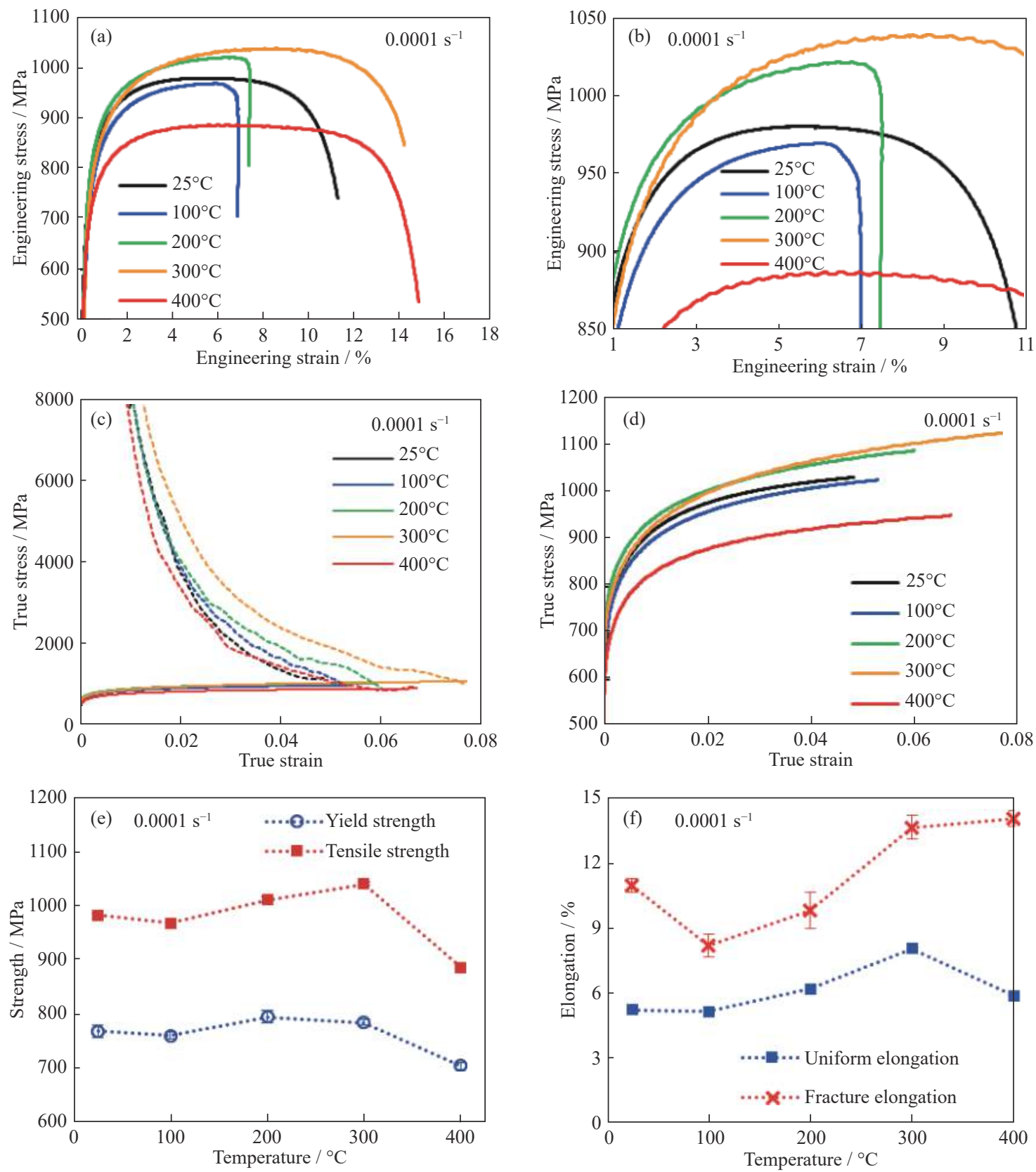

Fig. 2. Temperature dependence of the plastic deformation of DP1000: (a) engineering stress-strain curves at different temperatures; (b) zoom-in of (a); (c) flow curves and hardening curves until UTS points; (d) true stress-strain curves; (e) temperature dependence of strength; (f) temperature dependence of elongation.

error bars from all parallel tests. The DSA dominant region at $10^{-4} \mathrm{~s}^{-1}$ loading is $200-300^{\circ} \mathrm{C}$, whereas at $100^{\circ} \mathrm{C}$, the DSA probably has already appeared in accordance with the shortest FE; however, the thermal softening remains dominant on the stress level. In addition, the UE is only slightly decreased from RT to $100^{\circ} \mathrm{C}$ and keeps increasing with temperature until $300^{\circ} \mathrm{C}$. Compared with the decrease in $\mathrm{FE}$ at $100^{\circ} \mathrm{C}$, the shortening of the post-necking elongation mainly contributes to the total elongation reduction. On the contrary, the UTS is always enhanced from 100 to $300^{\circ} \mathrm{C}$, whereas the YS first increases when the temperature changes from RT to $200^{\circ} \mathrm{C}$ and then decreases when the temperature increases from 200 to $300^{\circ} \mathrm{C}$. The effect of DSA is also dependent on plastic strain, indicating that DSA-induced thermal hardening strength is distinct at $300^{\circ} \mathrm{C}$. For $400^{\circ} \mathrm{C}$, the smaller YS and UTS and the larger UE and FE than those at RT indicate a clear thermal softening behavior. In summary, the DSA starts at approximately $100^{\circ} \mathrm{C}$ and ends after $300^{\circ} \mathrm{C}$ under the quasistatic condition.

For bcc metals, at relatively low temperatures ( $\mathrm{RT}<T<$ $0.5 T_{\mathrm{m}}$, where $T_{\mathrm{m}}$ indicates the melting temperature) and low strain rates (quasistatic to intermediate), the dislocation 
movement is the basic plastic deformation mechanism. In an ideal situation, dislocation movement is only constrained by the crystal lattice obstruction, i.e., Peierls stress. When ambient temperature increases, the thermal activation contributes to reducing the critical resolved shear stress for dislocation movement and results in the thermal softening of macroscopic strength. However, when DSA appears, the interaction between dislocation movement and solute atoms, especially the interstitial elements, e.g., $\mathrm{C}$ or $\mathrm{N}$ atoms, becomes nonnegligible, thus bringing complex temperature responses on mechanical properties. During plastic deformation, the solute atoms tend to segregate to the dislocations. The diffusion rate of the solute atoms is strongly controlled by temperature, whereas the dislocation movement rate is mainly determined by the plastic strain rate. At a certain strain rate, the diffusion rate of the solute atoms increases with elevating temperature. When it becomes comparable with the mobility of the dislocations, solute atoms have enough time to diffuse with dislocation movement and adhere to the dislocation core when it is waiting before an obstacle, ultimately restricting dislocation movement. Accordingly, externally applied stress is required to free the dislocations and produce further plastic deformation. The alternating adhesion and release process leads to the serrated flow stress and distinct strain localization on sample surfaces. In addition, at a certain DSA temperature, the accumulated plastic strain results in an increase in dislocation density and an interaction opportunity between dislocations and solute atoms, thus enhancing the DSA effect.

Regarding the elongation and ductility, around the DSA starting temperature, DSA-induced embrittlement comes from the extremely short post-necking elongation, which can be explained by the DSA-related strong surface localization and defects in some studies [13,50]. From the compensation between the strength-ductility point of view, once the dislocation is locked by the solute cloud, it needs high stress to remove the pinning at relatively low DSA temperatures. If the required strength is too high, then the plastic deformation is difficult to sustain, and failure happens. However, explaining the enhanced ductility at a high DSA temperature, e.g., $300^{\circ} \mathrm{C}$, is difficult. The authors hypothesize that as thermal activation contributes to solute atom diffusion and dislocation movement at a high temperature, the necessary external stress for dislocations to move away from the solute cloud is low. Hence, the repeated pinning and detachment process between solute cloud and dislocation could be easily sustained and more homogeneously distributed in the entire uniform region, strongly contradicting the strong surface localization dominating at 100 and $200^{\circ} \mathrm{C}$. As a result, the enhanced UTS/YS ratio, as well as the enlarged uniform and post-necking elongation, are presented at $300^{\circ} \mathrm{C}$. These aforementioned explanations on the complex temperature effects are only based on the theoretical understanding of the dislocation-related plastic deformation mechanism. Substan- tial demonstrations shall be based on reliable experimental observations, e.g., in situ TEM for dislocation investigation during deformation. However, the elevating temperature might increase the challenges of the current experimental techniques.

\subsection{DSA behavior of DP1000 steel under extended stress states from uniaxial tension}

To investigate the temperature and DSA effect under other stress states, tests with the featured fracture specimens in Fig. 1 are analyzed. Fig. 3(a) takes the NDBR6 as an example of the measured force-displacement curves at different temperatures. From the force-displacement curves, characteristic features, such as peak force, peak-force displacement, and fracture displacement, are investigated for all stress states, as shown in Figs. 3(b)-3(d). The average values with error bars are plotted to consider all parallel tests. In Fig. 3(b), the normalized peak force of all the specimens at different temperatures is presented. The peak forces of different specimens at RT are chosen as the reference, therefore leading to unity for all the tests at RT in the plot. A general V-shaped trend in terms of the force response is similar to the uniaxial tensile test. For all fracture tests, the peak force first drops when the temperature rises from 25 to $100^{\circ} \mathrm{C}$ and then increases when it changes from 100 to $300^{\circ} \mathrm{C}$ with the maximum peak force always at $300^{\circ} \mathrm{C}$. The clear thermal hardening behavior of all geometries indicates that the DSA effect occurs in all tests. However, the quantitative trend of the DSA influence is not completely the same for varying stress states. For example, the rate of increase in peak force from RT to $300^{\circ} \mathrm{C}$ is only approximately $1 \%$ for PS tension (PSR16) but above 5\% for NDBR6, and both $\mathrm{SH}$ and $\mathrm{CH}$ perform the intermediated increase in peak force. Shen et al. [14] reported that the DSA effect is anisotropic for certain bainitic steels, and the current findings imply that the DSA effect might be stress state dependent as well. However, the force response to temperature changes is decided by material behavior and sample geometries, and a detailed study relying on the constitutive stress-strain relation must be performed to draw further quantitative conclusions.

Analogous to the uniform strain in the uniaxial tensile tests, the displacements at the peak-force point generally increase with elevated temperatures, as shown in Fig. 3(c), and the rate of increase could reach $40 \%$ at $300^{\circ} \mathrm{C}$ compared with RT. Only a little fluctuation is observed at approximately $100^{\circ} \mathrm{C}$ for NDBR50 and PSR16, with a decrease within $10 \%$ from RT. Concerning the ductile fracture, fracture displacement always presents a minimum value at $200^{\circ} \mathrm{C}$ (Fig. 3(d)), indicating the severe blue brittleness caused by DSA. Compared with the increased peak-force displacement from 100 to $300^{\circ} \mathrm{C}$, the DSA-induced embrittlement is related to the shortened post-peak-force process. In addition, as shown in Figs. 3(b)-3(d), a strong stress-state dependence of the DSA- 

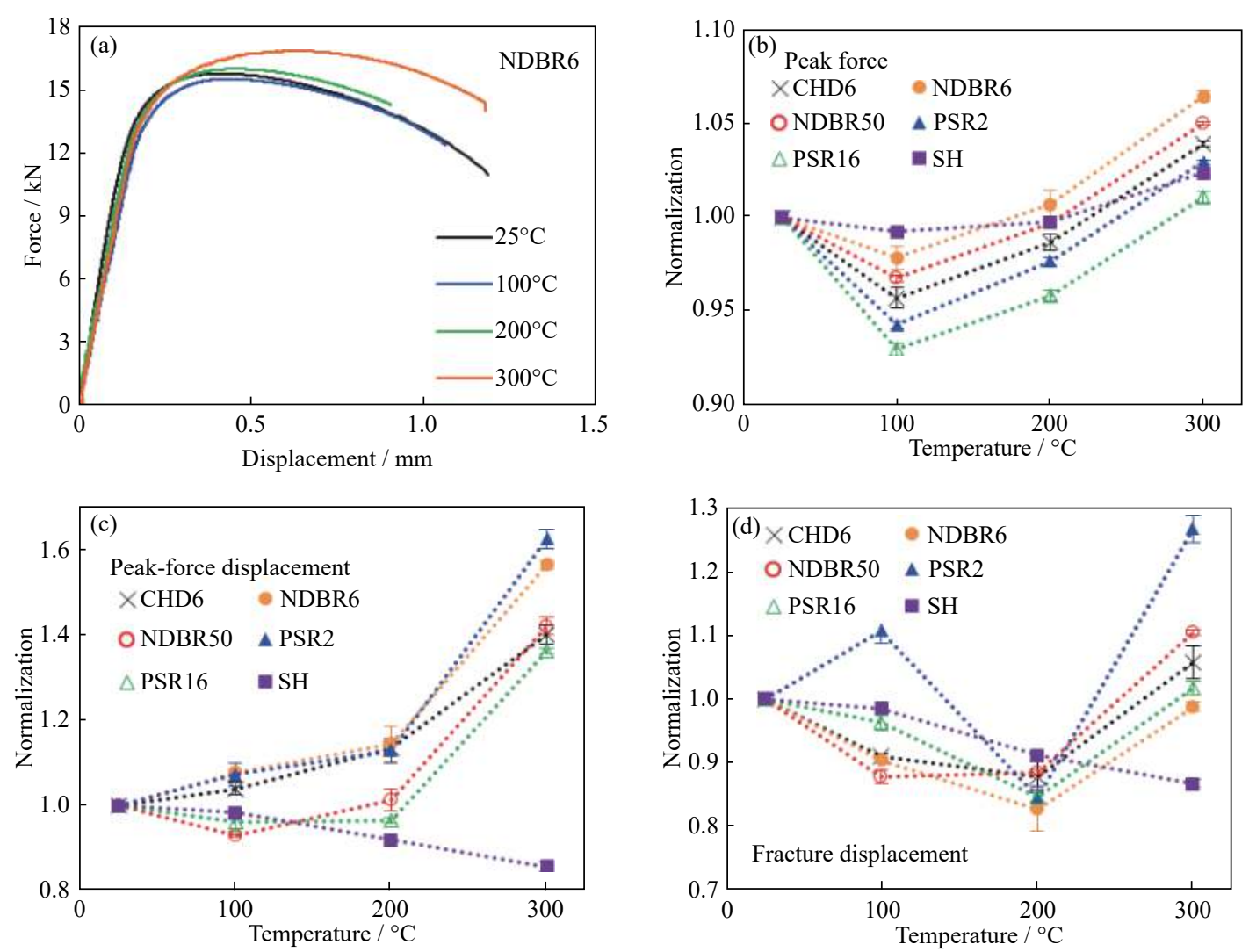

Fig. 3. Temperature dependence of featured stress state specimens: (a) force-displacement curves of NDBR6; (b) normalized peak force; (c) peak-force displacement; (d) fracture displacement.

induced brittleness can be observed. First, shear is an exception as the significant opposite tendency on ductility is presented with SH specimens. With the Lode angle parameter and stress triaxiality close to zero, the ductility always reduces when the temperature changes from RT to $300^{\circ} \mathrm{C}$. The shortest post-peak-force displacement still occurs at $200^{\circ} \mathrm{C}$ but with limited deviation compared with other temperatures. This limited deviation may be due to the fact the total ductility under shear condition is dominated by the elongation before peak force because its stress state and designed geometry induce the significantly delayed localization and fast fracture, and the short macroscopic localization stage cannot decide the ductility anymore. Considering the PS and NDBR6 tension with the similar Lode angle parameter as $\mathrm{SH}$, the improved ductility at $300^{\circ} \mathrm{C}$ remains limited, and the NDBR6 specimen even obtains a shorter fracture displacement at $300^{\circ} \mathrm{C}$ than RT. That is, their sensitivity to fracture is much less. When the Lode angle parameter moves to one, the $\mathrm{CH}$ and NDBR50 show a distinct increase in fracture displacement at $300^{\circ} \mathrm{C}$. In addition, stress triaxiality plays a role in this increase because the PSR2 specimen that owns the highest stress triaxiality also shows a distinctly promoted fracture displacement at $300^{\circ} \mathrm{C}$. An interesting point is that this condition still holds a reduced post-peak-force displacement compared with RT and $100^{\circ} \mathrm{C}$, but it performs the longest peak-force displacement at the same time. As high stress triaxiality and the Lode angle parameter tend to improve the fracture displacement at $300^{\circ} \mathrm{C}$, the competition between these two aspects exists and results in the complex performance pattern of all stress states. Analogous to smooth tensile testing, a clear physical and quantitative explanation on the complex DSA effect on ductility is still missing, but it can be concluded that the promoted ductility is contributed from the postponed localization and necking, whereas the embrittlement is caused by the fast post-necking process.

\subsection{Fractography analysis of failure under variable loading conditions}

The SEM observation on the fracture surfaces of specimens at different temperatures is shown in Fig. 4. The fractographs are taken at the critical damage initiation point in each geometry to indicate the specific stress state. At RT, as discussed in the previous study [48], the investigated DP1000 steel shows a void-controlled ductile fracture mechanism. In terms of void growth and coalescence, the $\mathrm{CH}$ and NDB specimens are dominated by the dimple fractures. Their fracture surfaces are full of primary and secondary voids. The contradictory results are shown in the $\mathrm{SH}$ specimens, where the shear/slip fracture is the main mechanism accompanied by limited primary voids. The PS specimens exhibit the combin- 

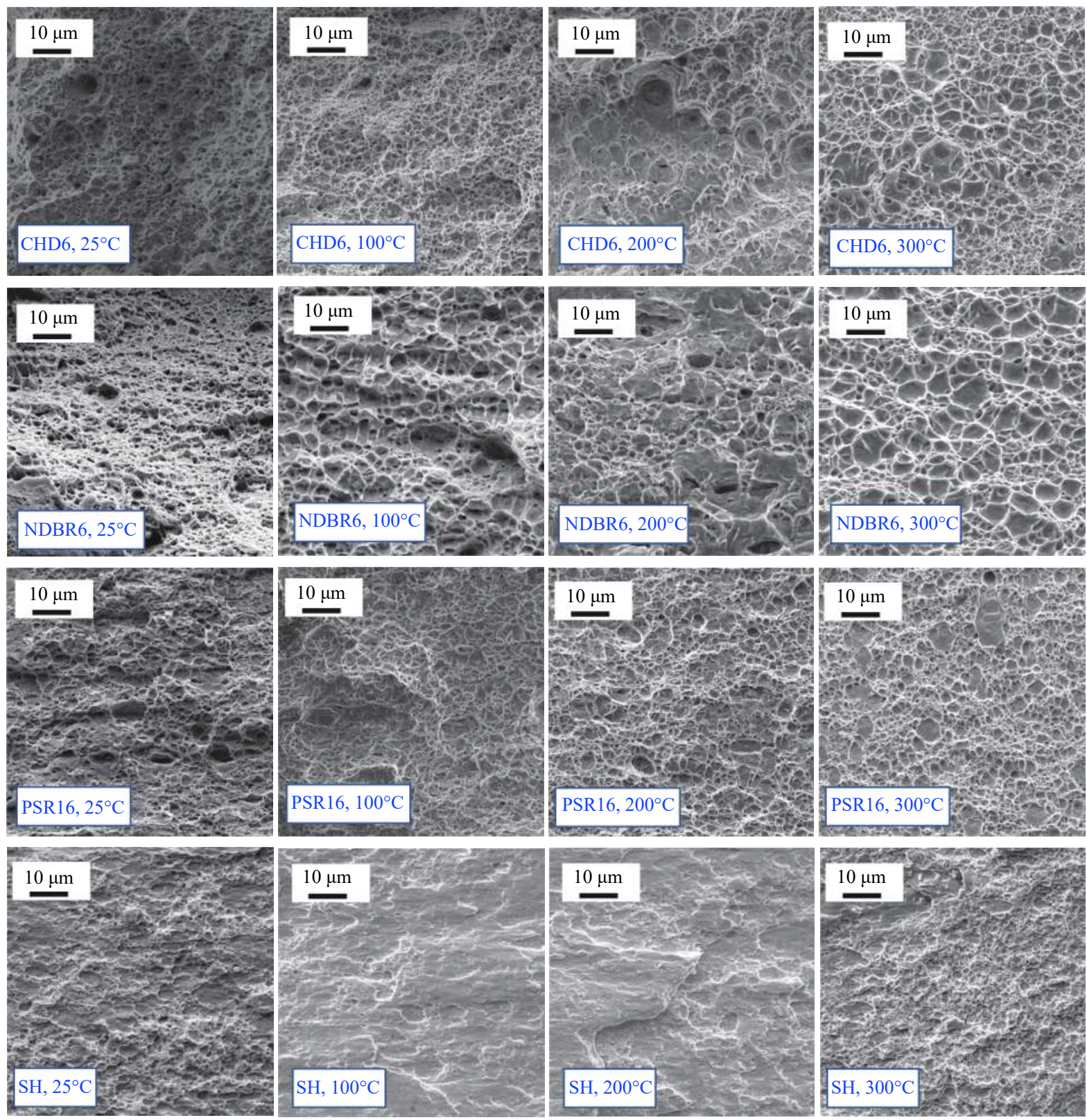

Fig. 4. Damage mechanism of DP1000 — SEM fractographs of fractured specimens under variable stress states and temperatures.

ation of the dimple and slip fracture.

In terms of temperature effects, for $\mathrm{CH}$, when the temperature increases from RT to $200^{\circ} \mathrm{C}$, the distinctly enlarged and deepened primary voids on the rugged fracture surface can be observed. Furthermore, the link between primary voids is shear instead of secondary voids at RT and $100^{\circ} \mathrm{C}$. This result proves the evident drag on the internal surface edge of the voids, corresponding to the locked dislocation movement in the DSA blue brittleness region. At $300^{\circ} \mathrm{C}$, the fracture surface becomes smoother as the voids become shallower. The nested and overlapped large void structure and the closepacked fine dimple zone are observed. This might be related to the repeated dislocation and solute atom interaction and the improved ductility of $\mathrm{CH}$ at $300^{\circ} \mathrm{C}$. Regarding NDB tension, the enlarged voids have already occurred at $100^{\circ} \mathrm{C}$. At $200^{\circ} \mathrm{C}$, the shear mode is promoted while being accompanied by deep and elliptical voids. Moreover, the contiguous shear zones are easy to link with each other and form the final crack path, thus verifying the distinct ductility loss. At $300^{\circ} \mathrm{C}$, the glossy inner surface of primary voids is also similar to shear mode, which is responsible for the slightly shorter fracture displacement and distinctly reduced post-peakforce displacement compared with RT. However, compared with $\mathrm{CH}$, the concentrated fine dimples disappear in NDB at $300^{\circ} \mathrm{C}$. Similar behavior is observed in the PS specimen. Given the fast damage and fracture process, the generally smaller void size is observed in PS. For PSR16, the severest shortening of post-peak-force stage occurs at $300^{\circ} \mathrm{C}$, corres- 
ponding to the reduced void depth on the fractography. In terms of $\mathrm{SH}$, as aforementioned in Section 3.2, the total ductility is mainly controlled by before-necking behavior, which is difficult to distinguish from the fractographs. Thus, the focus is the post-peak-force displacement, which shows a minimum point at $200^{\circ} \mathrm{C}$ but a maximum value at $300^{\circ} \mathrm{C}$. The fractographs prove that the specimen at $300^{\circ} \mathrm{C}$ presents the largest fraction of fine dimples, whereas almost pure shear bands dominate the fracture surface at 100 and $200^{\circ} \mathrm{C}$. In conclusion, the formation of shear mode is related to the reduced post-necking ductility in the DSA region, whereas improved ductility is normally accompanied by fine dimples.

\subsection{Microstructure-sensitive damage mechanism analys- is in conjunction with DSA behavior}

In the investigated DP1000, the main damage mechan- isms are the ferrite-martensite interface debonding and martensite cracking according to the previous study [48]. At RT, shear with low stress triaxiality and Lode angle parameter promotes martensite cracking, whereas high stress triaxiality and Lode angle parameter are prone to ferrite-martensite debonding. Here, the temperature effects on damage mechanisms under different stress states are discussed.

Fig. 5 presents the temperature effects coupled with stress states on the microstructure-sensitive damage mechanism of DP1000. Generally, for CH, NDB, and PS specimens, the number of microdefects at the blue temperatures, i.e., $100-200^{\circ} \mathrm{C}$, is distinctly increased. Meanwhile, the enlarged or elongated defects also indicate the evident void growth and coalescence process, which shall be responsible for the shortened post-peak-force stage. Regarding grain deformation, if the shape factor or aspect ratio is defined as the length
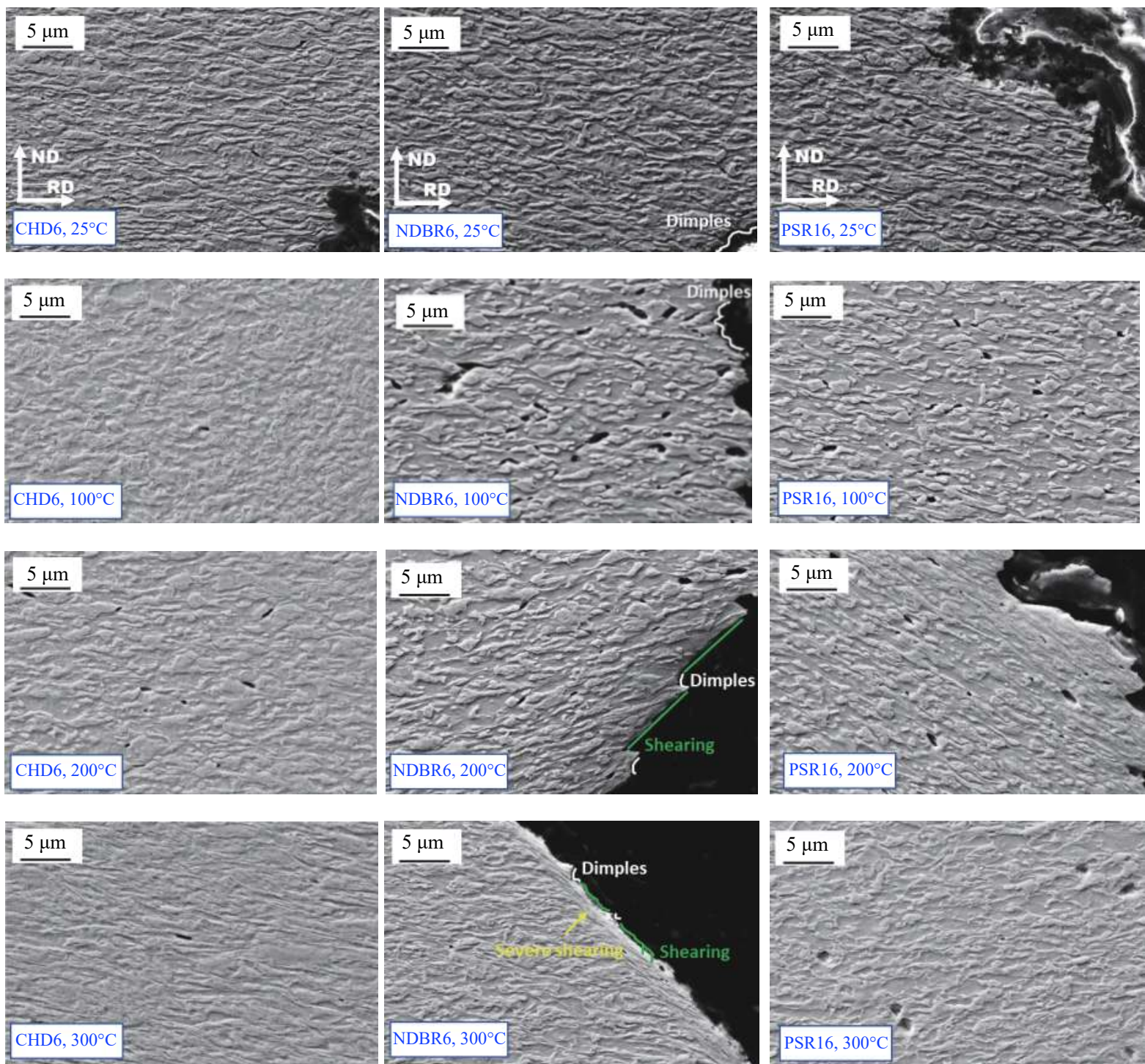

Fig. 5. Microstructure-sensitive damage mechanism of DP1000 at different temperatures-SEM micrographs on the ND-RD plane of the fractured $\mathrm{CH}, \mathrm{NDB}$, and PS specimens. 
ratio of the minor axis to the major axis of the ellipse-fitted grain [45] in tensile specimens, then the smaller the shape factor, the larger the elongation rate of deformed grain. After the fracture, the macroscopic necking behavior is clear for all $\mathrm{CH}$, NDB, and PS specimens. Even for SH, a small thinning zone within $200-300 \mu \mathrm{m}$ is still observed. That is, the focused observation zones beneath the fracture surface are elongated at the macroscopic uniform deformation and postnecking stages. Therefore, investigating only the microstructure evolution at peak-force displacement is difficult. However, grain elongation still provides some hints for evaluating the final ductility behavior. For $\mathrm{CH}$, NDB, and PS, the elongated grains with the smallest shape aspect ratio are observed at $300^{\circ} \mathrm{C}$, indicating the increasing peak-force displacement and relatively large fracture displacement at $300^{\circ} \mathrm{C}$. The debonding at phase boundaries is the main mechanism for CHD6, but the martensite cracking appears at $200^{\circ} \mathrm{C}$. Similar behavior in terms of defect number, void size and shape, grain elongation rate, and damage mechanism change is exhibited in NDBR6. In addition, the boundary shape of the longitudinal section on the fracture surface verifies the dimple/shearing morphology observed from the SEM fractographs in Fig. 4. For instance, the dimple-dominant fracture surface with some deep primary voids is presented for NDBR6 specimens at RT and $100^{\circ} \mathrm{C}$, and a clear curvature can be observed along the longitudinal section boundary, which is marked with white wavy lines in Fig. 5. When the temperature is increased to $200^{\circ} \mathrm{C}$, the shearing occurrence brings relatively long and straight boundary lines (marked with green lines), and the lateral profiles of some deep elliptical voids are observed simultaneously. At $300^{\circ} \mathrm{C}$, the flat fracture surface with fine ripples is presented, and the severe shearing behavior is shown near the fracture surface. That is corresponding to the shearing formed inner surface of primary voids and the reduced void depth in Fig. 4. Regarding PS specimens, interface deboning and martensite cracking are observed at RT due to its low Lode angle parameter [48]. Furthermore, martensite cracking is enhanced at $100-200^{\circ} \mathrm{C}$. In addition, the extremely sheared grains along the fracture surface profiles are presented at 200 and $300^{\circ} \mathrm{C}$. All these phenomena prove the shortened post-necking stage and fast fracture behavior in the DSA region.

In terms of $\mathrm{SH}$, the SEM micrographs with two image magnifications are shown in Fig. 6 to investigate the shearing behavior of grains and the microdefects under the fracture surface with the RD, i.e., loading direction, indicated for each specimen. Except for a few inclusion-related or samplepreparation-induced voids/cracks, the microdefects are limited in SH specimens. This finding verifies the extremely short post-necking stage and the fast fracture in SH. Except for inclusions, the dominant microstructure damage mechanism is still martensite cracking for all $\mathrm{SH}$ conditions. The fracture surface boundary is wavy with curvy dimple profiles at RT and $300^{\circ} \mathrm{C}$, and it becomes flat at $100-200^{\circ} \mathrm{C}$. This result is consistent with the observation of fractographs of $\mathrm{SH}$ in Fig. 4, and it might imply that the voids of the SH specimens could be simply created by the uneven connections of the internal shear fracture rather than by the normal void growth under high stress triaxiality. Further investigation with an in situ testing method would provide further hints on this hypothesis. The simple shear stress state causes the rotation of the material coordinates. In accordance with the marked loading direction (i.e. RD) on the micrographs, the distinct grain rotation can be observed, especially in the region close to the fracture surface. The rotated grains are only concentrated within the zone around $10 \mu \mathrm{m}$ away from the fracture surface at RT. Then, with temperature increases, the rotation area also increases. The rotation area finally reaches near 100 $\mu \mathrm{m}$ at $300^{\circ} \mathrm{C}$. Combined with the decreased ductility from RT to $300^{\circ} \mathrm{C}$, it is concluded that the contribution of shear rotation to global elongation is limited. Generally, reduced ductility always relates to promoted martensite cracking in the microstructure and the appearance of shear mode regardless of loading condition.

\section{Conclusions}

(1) Under quasistatic loading, the DP1000 steel exhibits a distinct DSA effect at a specific range of temperature and plastic strain under uniaxial tensile loading and general stress states. DSA generally starts at $100^{\circ} \mathrm{C}$ and is enhanced at $200-300^{\circ} \mathrm{C}$. The effect fades away when the temperature rises to $400^{\circ} \mathrm{C}$.

(2) DSA brings thermal hardening, i.e., enhanced strength with increasing temperature and wavy strain hardening behavior. In terms of ductility, blue brittleness is observed at low DSA temperatures $\left(100-200^{\circ} \mathrm{C}\right)$ with short post-necking elongation. Surprisingly, the improved ductility accompanied by enhanced strength is also present at a high DSA temperature $\left(300^{\circ} \mathrm{C}\right)$. This result provides a new design rule for materials in specific applications by engineering the DSA effects.

(3) DSA behavior is highly stress-state dependent as the quantitative trend of DSA influence is not completely the same for varying stress states. The dependency applies to the strength and fracture behavior of DSA. Either higher Lode angle parameter or stress triaxiality tends to limit the blue brittleness behavior.

(4) For CH, NDB, and PS specimens, the reduced ductility at blue temperatures is generally accompanied by the enlarged void size and increased shear mode on the fracture surface. From a microstructure-sensitive perspective, more and larger microdefects and martensite cracking are observed in this temperature range.

(5) Shear specimen with the lowest Lode angle parameter and stress triaxiality strongly prohibits necking and promotes 

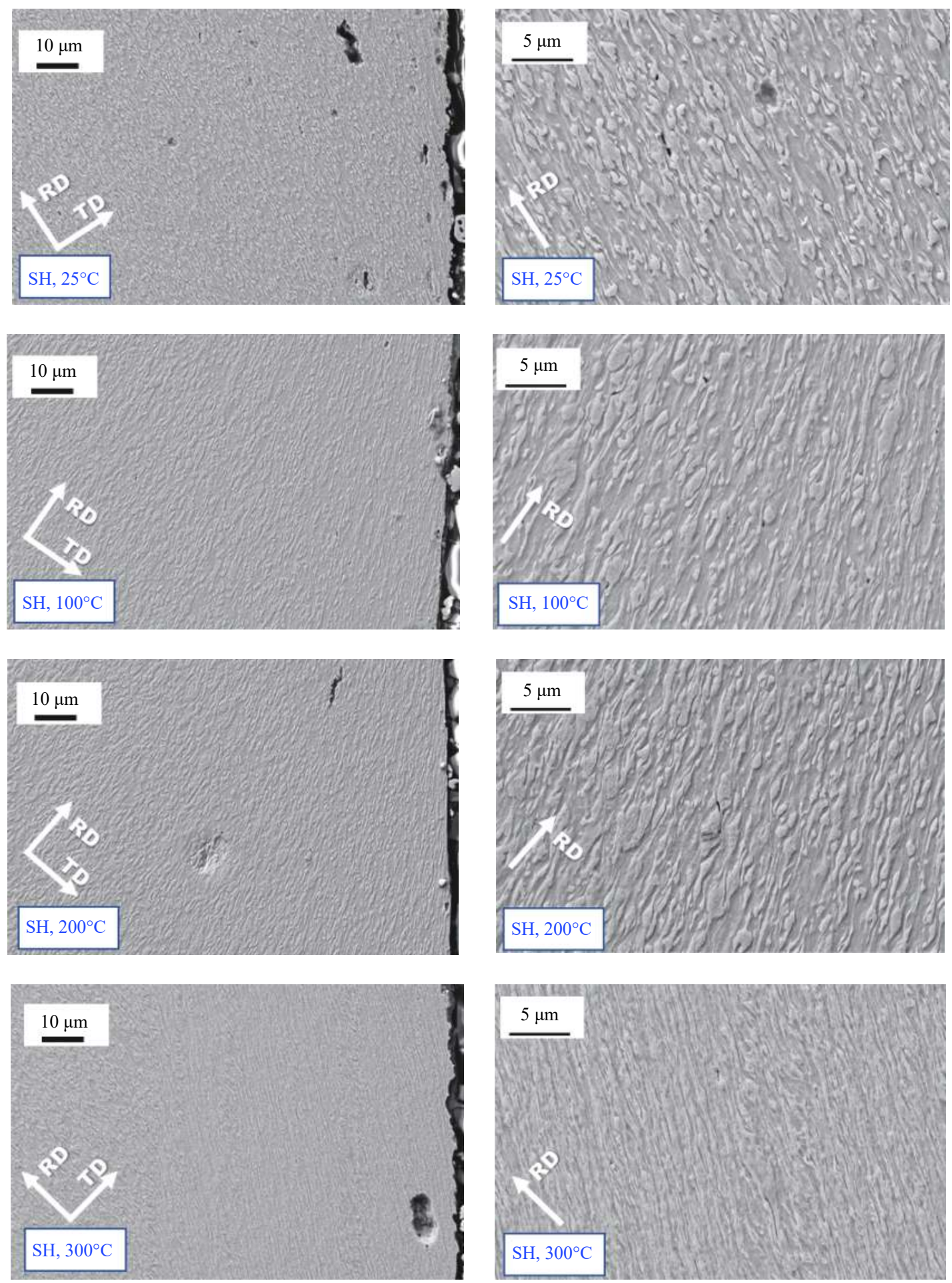

Fig. 6. Microstructure-sensitive damage mechanism of DP1000 at different temperatures-SEM micrographs on the RD-TD plane of SH specimens with different magnifications.

a fast fracture. Its ductility is determined by the before-necking stage, which reduces with increasing temperature. The damage mechanism changes from a mixture of dimple and shear modes to pure shear when the ductility is reduced at 100 and $200^{\circ} \mathrm{C}$. However, even though the small dimples are observed at $300^{\circ} \mathrm{C}$, it still shows minimum fracture displace- ment, which might be related to the enhanced shearing rotation.

\section{Acknowledgements}

The authors gratefully acknowledge the valuable com- 
ments by Prof. Sebastian Münstermann from Steel Institute (IEHK), RWTH Aachen University, Germany. The work has been supported by the European Commission Research Fund for Coal and Steel (No. 709711). Wenqi Liu is grateful to Shujing Li and Guangming Zeng from IEHK for data processing.

\section{Open access funding provided by Aalto University.}

Open Access This article is licensed under a Creative Commons Attribution 4.0 International License, which permits use, sharing, adaptation, distribution and reproduction in any medium or format, as long as you give appropriate credit to the original author(s) and the source, provide a link to the Creative Commons licence, and indicate if changes were made. The images or other third party material in this article are included in the article's Creative Commons licence, unless indicated otherwise in a credit line to the material. If material is not included in the article's Creative Commons licence and your intended use is not permitted by statutory regulation or exceeds the permitted use, you will need to obtain permission directly from the copyright holder. To view a copy of this licence, visit http://creativecommons.org/licenses/by/4.0/.

\section{References}

[1] J.D. Baird, Strain aging of steel: A critical review, Iron Steel, 36(1963), p. 186.

[2] A. Keh, Y. Nakada, and W. Leslie, Dynamic strain aging in iron and steel, [in] Dislocation Dynamics, Mc Graw-Hill, New York, 1968, 381.

[3] J.D. Baird, The effects of strain-ageing due to interstitial solutes on the mechanical properties of metals, Metall. Rev., 16(1971), No. 1, p. 1.

[4] W.C. Leslie, Iron and its dilute substitutional solid solutions, Metall. Mater. Trans. B, 3(1972), No. 1, p. 5.

[5] M.J. Roberts and W.S. Owen, Unstable flow in martensite and ferrite, Metall. Trans., 1(1970), p. 3203.

[6] A.W. Sleeswyk, Slow strain-hardening of ingot iron, Acta Metall., 6(1958), No. 9, p. 598.

[7] A.H. Cottrell and B.A. Bilby, Dislocation theory of yielding and strain ageing of iron, Proc. Phys. Soc. A, 62(1949), No. 1, p. 49.

[8] A.H. Cottrell, M.A. Jaswon, and N.F. Mott, Distribution of solute atoms round a slow dislocation, Proc. R. Soc. London Ser. A, 199(1949), No. 1056, p. 104.

[9] A.P.a.F.L. Chatelier, A phenomenon observed during the tensile test alloys during processing, C. R. Acad. Sci., 176(1923), p. 507.

[10] G. Mima and F. Inoko, A study on the blue-brittle behaviour of a mild steel in torsional deformation, Trans. Jpn. Inst. Met., 10(1969), No. 3, p. 227.

[11] I.E. Dolzhenkov, Influence of deformation rate on the blue brittleness temperature and dislocation density of carbon steel, Met. Sci. Heat Treat., 9(1967), No. 6, p. 423.

[12] J.G. Kim, S. Hong, N. Anjabin, B.H. Park, S.K. Kim, K.G. Chin, S. Lee, and H.S. Kim, Dynamic strain aging of twinninginduced plasticity (TWIP) steel in tensile testing and deep drawing, Mater. Sci. Eng. A, 633(2015), p. 136.

[13] L. Chen, H.S. Kim, S.K. Kim, and B.C. De Cooman, Localized deformation due to Portevin-LeChatelier effect in $18 \mathrm{Mn}-0.6 \mathrm{C}$
TWIP austenitic steel, ISIJ Int., 47(2007), No. 12, p. 1804.

[14] F.H. Shen, S. Münstermann, and J.H. Lian, An evolving plasticity model considering anisotropy, thermal softening and dynamic strain aging, Int. J. Plasticity, 132(2020), art. No. 102747.

[15] X.Y. Li, C.C. Roth, and D. Mohr, Machine-learning based temperature- and rate-dependent plasticity model: Application to analysis of fracture experiments on DP steel, Int. J. Plasticity, 118(2019), p. 320.

[16] S.G. Hong and S.B. Lee, Dynamic strain aging under tensile and LCF loading conditions, and their comparison in cold worked 316L stainless steel, J. Nucl. Mater., 328(2004), No. 23, p. 232.

[17] V.S. Srinivasan, M. Valsan, R. Sandhya, K. Bhanu Sankara Rao, S.L. Mannan, and D.H. Sastry, High temperature time-dependent low cycle fatigue behaviour of a type $316 \mathrm{~L}(\mathrm{~N})$ stainless steel, Int. J. Fatigue, 21(1999), No. 1, p. 11.

[18] C. Gupta, J.K. Chakravartty, S.L. Wadekar, and S. Banerjee, Fracture behaviour in the dynamic strain ageing regime of a martensitic steel, Scripta Mater., 55(2006), No. 12, p. 1091.

[19] A.R. Das, T. Chowdhury, S. Sivaprasad, H.N. Bar, N. Narasaiah, and S. Tarafder, Influence of dynamic strain ageing on fracture behaviour and stretch zone formation of a reactor pressure vessel steel, Int. J. Fract., 202(2016), No. 1, p. 79.

[20] R. Mohan and C. Marschall, Cracking instabilities in a low-carbon steel susceptible to dynamic strain aging, Acta Mater., 46(1998), No. 6, p. 1933.

[21] P. Verma, G. Sudhakar Rao, P. Chellapandi, G.S. Mahobia, K. Chattopadhyay, N.C. Santhi Srinivas, and V. Singh, Dynamic strain ageing, deformation, and fracture behavior of modified 9Cr-1Mo steel, Mater. Sci. Eng. A, 621(2015), p. 39.

[22] W. Karlsen, M. Ivanchenko, U. Ehrnstén, Y. Yagodzinskyy, and $\mathrm{H}$. Hänninen, Microstructural manifestation of dynamic strain aging in AISI 316 stainless steel, J. Nucl. Mater., 395(2009), No. 1-3, p. 156.

[23] B.M. Gonzalez, L.A. Marchi, E.J.D. Fonseca, P.J. Modenesi, and V.T.L. Buono, Measurement of dynamic strain aging in pearlitic steels by tensile test, ISIJ Int., 43(2003), No. 3, p. 428.

[24] A.R. Kohandehghan, A.R. Sadeghi, J.M. Akhgar, and S. Serajzadeh, Investigation into dynamic strain aging behaviour in high carbon steel, Ironmaking Steelmaking, 37(2010), No. 2, p. 155.

[25] D. Caillard and J. Bonneville, Dynamic strain aging caused by a new Peierls mechanism at high-temperature in iron, Scripta Mater., 95(2015), p. 15.

[26] D. Caillard, Dynamic strain ageing in iron alloys: The shielding effect of carbon, Acta Mater., 112(2016), p. 273.

[27] G.C. Soares, R.R.U. Queiroz, and L.A. Santos, Effects of dynamic strain aging on strain hardening behavior, dislocation substructure, and fracture morphology in a ferritic stainless steel, Metall. Mater. Trans. A, 51(2020), No. 2, p. 725.

[28] M.S. Shahriary, B. Koohbor, K. Ahadi, A. Ekrami, M. KhakianQomi, and T. Izadyar, The effect of dynamic strain aging on room temperature mechanical properties of high martensite dual phase (HMDP) steel, Mater. Sci. Eng. A, 550(2012), p. 325.

[29] H. Najam, M. Koyama, B. Bal, E. Akiyama, and K. Tsuzaki, Strain rate and hydrogen effects on crack growth from a notch in a Fe-high-Mn steel containing $1.1 \mathrm{wt} \%$ solute carbon, Int. $J$. Hydrogen Energy, 45(2020), No. 1, p. 1125.

[30] M. Srinivas, G. Malakondaiah, K.L. Murty, and P.R. Rao, Fracture toughness in the dynamic strain ageing regime, Scripta Metall. Mater., 25(1991), No. 11, p. 2585.

[31] A.S. Alomari, N. Kumar, and K.L. Murty, Enhanced ductility in dynamic strain aging regime in a $\mathrm{Fe}-25 \mathrm{Ni}-20 \mathrm{Cr}$ austenitic 
stainless steel, Mater. Sci. Eng. A, 729(2018), p. 157.

[32] S.J. Lee, J. Kim, S.N. Kane, and B.C.D. Cooman, On the origin of dynamic strain aging in twinning-induced plasticity steels, Acta Mater., 59(2011), No. 17, p. 6809.

[33] D.M. Field and D.C. Van Aken, Dynamic strain aging phenomena and tensile response of medium-Mn TRIP steel, Metall. Mater. Trans. A, 49(2018), No. 4, p. 1152.

[34] R.R.U. Queiroz, F.G.G. Cunha, and B.M. Gonzalez, Study of dynamic strain aging in dual phase steel, Mater. Sci. Eng. A, 543(2012), p. 84

[35] P.J. Ferreira, I.M. Robertson, and H.K. Birnbaum, Hydrogen effects on the interaction between dislocations, Acta Mater. 46(1998), No. 5, p. 1749.

[36] Z. Que, H.P. Seifert, P. Spaetig, A. Zhang, J. Holzer, G.S. Rao, and S. Ritter, Effect of dynamic strain ageing on environmental degradation of fracture resistance of low-alloy RPV steels in high-temperature water environments, Corros. Sci., 152(2019), p. 172.

[37] Z. Que, H.P. Seifert, P. Spaetig, J. Holzer, G.S. Rao, S. Ritter, and A. Zhang, Environmental degradation of fracture resistance in high-temperature water environments of low-alloy reactor pressure vessel steels with high sulphur or phosphorus contents, Corros. Sci., 154(2019), p. 191.

[38] X.Q. Wu and I.S. Kim, Effects of strain rate and temperature on tensile behavior of hydrogen-charged SA508 $\mathrm{Cl} .3$ pressure vessel steel, Mater. Sci. Eng. A, 348(2003), No. 1-2, p. 309.

[39] J.H. Lian, H.Q. Yang, N. Vajragupta, S. Münstermann, and W. Bleck, A method to quantitatively upscale the damage initiation of dual-phase steels under various stress states from microscale to macroscale, Comput. Mater. Sci., 94(2014), p. 245.

[40] B. Wu, N. Vajragupta, J. Lian, U. Hangen, P. Wechsuwanrnanee, and S. Muenstermann, Prediction of plasticity and damage initiation behaviour of $\mathrm{C} 45 \mathrm{E}+\mathrm{N}$ steel by micromechanical modelling, Mater. Des., 121(2017), p. 154.

[41] Q.G. Xie, J.H. Lian, J.J. Sidor, F.W. Sun, X.C. Yan, C.Y. Chen, T.K. Liu, W.J. Chen, P. Yang, K. An, and Y.D. Wang, Crystal- lographic orientation and spatially resolved damage in a dispersion-hardened Al alloy, Acta Mater., 193(2020), p. 138.

[42] J.S. He, J.H. Lian, G. Golisch, A. He, Y.D. Di, and S. Münstermann, Investigation on micromechanism and stress state effects on cleavage fracture of ferritic-pearlitic steel at $-196^{\circ}$ C, Mater. Sci. Eng. A, 686(2017), p. 134.

[43] J.H. Lian, P.F. Liu, and S. Münstermann, Modeling of damage and failure of dual phase steel in Nakajima test, Key Eng. Mater., 525-526(2012), p. 69.

[44] W.Q. Liu, J.H. Lian, S. Münstermann, C.Y. Zeng, and X.F. Fang, Prediction of crack formation in the progressive folding of square tubes during dynamic axial crushing, Int. J. Mech. Sci., 176(2020), art. No. 105534.

[45] W.Q. Liu, J.H. Lian, N. Aravas, and S. Münstermann, A strategy for synthetic microstructure generation and crystal plasticity parameter calibration of fine-grain-structured dualphase steel, Int. J. Plast., 126(2020), art. No. 102614.

[46] J.H. Lian, T. Wierzbicki, J.E. Zhu, and W. Li, Prediction of shear crack formation of lithium-ion batteries under rod indentation: Comparison of seven failure criteria, Eng. Fract. Mech., 217(2019), art. No. 106520.

[47] J.H. Lian, M. Sharaf, F. Archie and S. Münstermann, A hybrid approach for modelling of plasticity and failure behaviour of advanced high-strength steel sheets, Int. J. Damage Mech., 22(2013), No. 2, p. 188.

[48] W.Q. Liu, J.H. Lian, and S. Münstermann, Damage mechanism analysis of a high-strength dual-phase steel sheet with optimized fracture samples for various stress states and loading rates, Eng. Fail. Anal., 106(2019), art. No. 104138.

[49] British Standards Institution, BS EN ISO 6892-1:2016: Metallic Materials-Tensile Testing_Part1: Method of Test at Room Temperature, 2016.

[50] B.C. De Cooman, 10 - Phase transformations in high manganese twinning-induced plasticity (TWIP) steels, Phase Transformations Steels, 2(2012), p. 295. 